Archives of Urology

ISSN: 2638-5228

Volume 2, Issue 1, 2019, PP: 8-11

SRYPAHWA

\title{
Grade IV Renal Trauma in Pediatric Age Patient with a Solitary Kidney
}

\author{
Prof. Dr. Bakhtawar Gul, FRCS ${ }^{1}$, Dr. Riaz Ahmad Khan, FCPS ${ }^{2}$, Dr. Muhammad Izhar MBBS ${ }^{3}$, Dr. \\ Ifran Ullah Khan, FCPS ${ }^{4}$, Dr. Qaiser Iqbal, FCPS ${ }^{5}$ \\ 1,4,5Institute of Kidney Diseases Peshawar, Pakistan. \\ ${ }^{2}$ Assistant Professor, Institute of Kidney Diseases Peshawar, Pakistan. \\ ${ }^{3}$ Postgraduate Trainee, Institute of Kidney Diseases Peshawar, Pakistan. \\ riaz286@yahoo.com
}

*Corresponding Author: Dr. Riaz Ahmad Khan, FCPS, Assistant Professor, Institute of Kidney Diseases Peshawar, Pakistan.

Abstract

A nine-year-old male child with grade IV injury to the solitary kidney was referred to the Institute of kidney diseases Peshawar from a private clinic in the periphery with a history of fall on a saddle of the wooden door. Initially, the patient had visible hematuria and was hemodynamically stable. After conservative management, on the 2nd day of admission, his hematuria settled down. On the 9th day of his hospitalization, he was found symptoms free with normal renal functions.

Keywords: solitary kidney, renal trauma, Conservative Treatment

\section{CASE REPORT}

A nine-year-old male child was referred to accident and emergency department of the Institute of Kidney Diseases (IKD) Peshawar. Previously he was examined in a private clinic in Mardan Khyber Pakhtunkhwa. Upon his arrival at IKD, the patient was thoroughly examined, investigated and was then hospitalized (see Appendix A).

At the time of admission, this patient was responsive and vitally stable except tachycardiac with a pulse of $120 / \mathrm{min}$. He was complaining of right-sided flank and epigastric pain. Ultrasound was done which showed Post-traumatic avascular right renal partially separated upper pole with intra and perinephric/ subcapsular hematoma. As shown in the Figures 1 and 2, CT Scan of the pelvis abdomen and pelvis and Doppler ultrasound revealed right renal injury with the shattered upper half of right kidney along with peri and para renal hematoma, hemorrhagic ascites and peri and para renal fluid collection demonstrating pelvicalyceal contrast extravasation concerning for
urinoma(Grade IV renal injury). The left kidney was not visualized (congenital agenesis).

Renal functions were normal (urea $=41 \mathrm{mg} / \mathrm{dl}$, serum creatinine $=0.9 \mathrm{mg} / \mathrm{dl}$ ). The patient was catheterized and advised strict bed rest and was started on IV fluids and antibiotics. Initially patient was having visible hematuria which was settled down on the 2nd day of admission. He was shifted to the Intensive care unit with strictly monitoring his vitals and intake output record.

Renal functions were normal (urea $=41 \mathrm{mg} / \mathrm{dl}$, serum creatinine $=0.9 \mathrm{mg} / \mathrm{dl}$ ). The patient was catheterized and advised strict bed rest and was started on IV fluids and antibiotics. Initially patient was having visible hematuria which was settled down on the 2 nd day of admission. He was shifted to the Intensive care unit with strictly monitoring his vitals and intake output record. As the patient vitals were stable therefore, a conservative approach was chosen. He was transfused with 150 cc of whole blood. Patient Doppler ultrasound was done on a daily basis with a regular 
Grade IV Renal Trauma in Pediatric Age Patient with a Solitary Kidney

check of hematocrit level. He did well and responded to our conservative management. On the 9th day of the admission ultrasound KUB showed very minimal Right intraparenchymal and perinephric hematoma with upper pole laceration and loss of vascularity. Per urethral catheter was removed and the patient was encouraged to mobilize and observed for 24 hours for any episodes of hematuria. He was discharged on home treatment with advice to avoid physical exertion and regular follow up in OPD weekly.

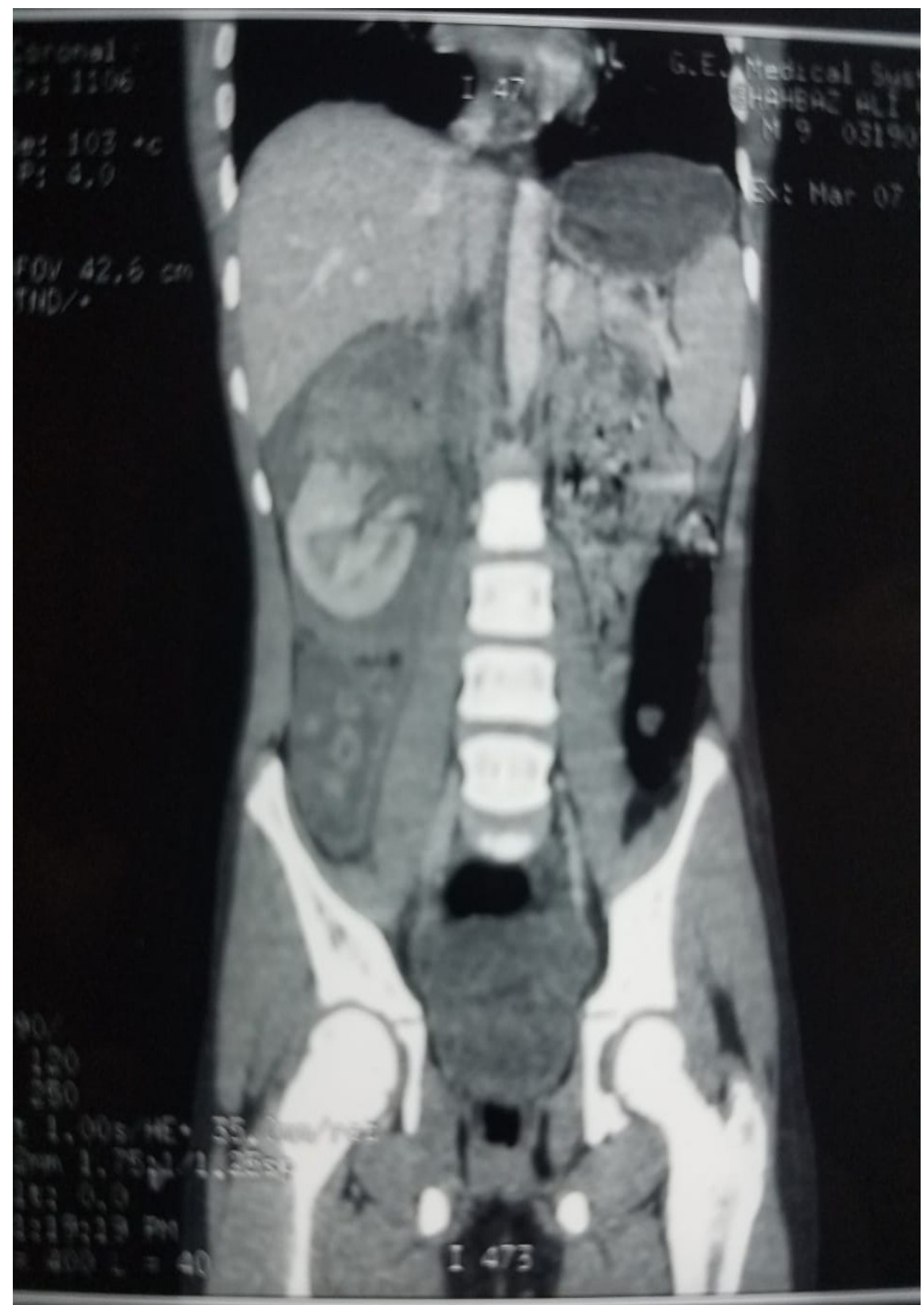

Figure 1. shattered upper pole of right solitary kidney 


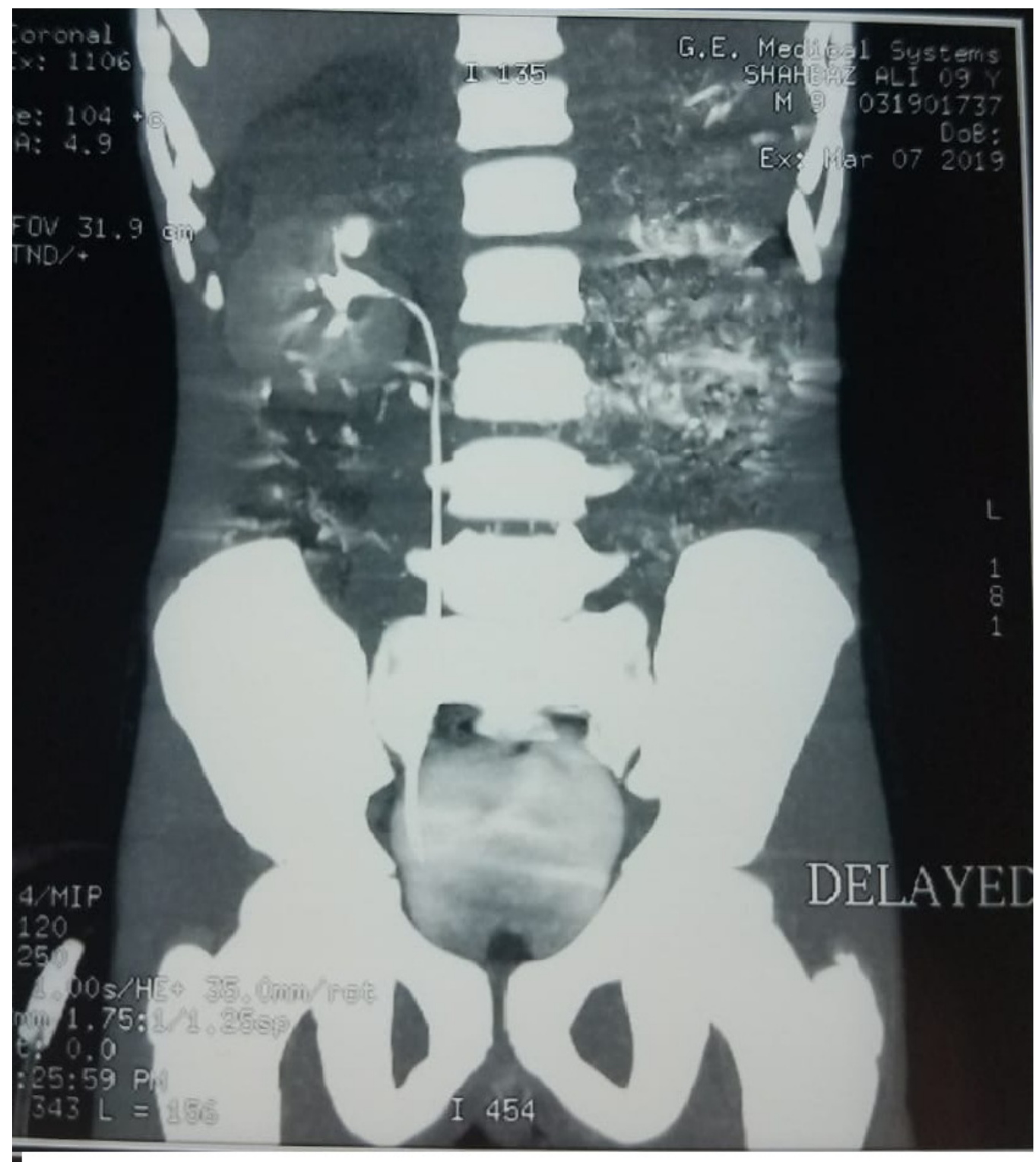

Figure 2. Grade IV renal injury

\section{DISCUSSION}

As per AAST guidelines, renal injuries are rated on a five-point scale from I to $\mathrm{V}$ anchored as grades. Generally, non-operative procedures are utilized in case of grade I to III. However, grade V renal trauma is managed surgically including exploration and repair. It is further worthwhile to mention that in terms of patients with grade IV renal trauma research evidences are limited on the role and timing of surgical, urological and radiographic intervention and thus arguable [1]. However, the available and accessible research findings recommend conservative management for grade IV and V. To this end the success rate has been recorded within the range from forty to eighty four percent [2]. In addition to that the AUA-American Urological Association guidelines also demonstrate that conservative management should be adopted in hemodynamically stable patients with grade IV and V injuries [3]. Likewise, the EAU- European Association of Urology guidelines also propose conservative management in the context of grade $\mathrm{V}$ renal trauma if hemodynamically stable. In the other words these guidelines suggest to avoid surgical intervention in grade $\mathrm{V}$ renal trauma [4]. Based on the preceding discussions, the intended case report identified our patient hemodynamically stable and therefore was treated conservatively. However, we rigorously 
monitored his vitals, intake output record and further advised the patient to take strict bed rest. The long term consequences have not been addressed in our case owing to the on-going follow up of this patient. It has been proposed that the onset of hypertension and altered renal functions are consequences to previous high-grade renal trauma [5] [6].

\section{REFERENCES}

[1] Shoobridge JJ, Corcoran NM, Martin KA, Koukounaras J, Royce PL, Bultitude MF. Contemporary management of renal trauma. Rev Urol 2011; 13: 65-72.

[2] Fitzgerald CL, Tran P, Burnell J, Broghammer JA, Santucci R. Instituting a conservative management protocol for pediatric blunt renal trauma: evaluation of a prospectively maintained patient registry. J Urol 2011; 185: 1058-64.
[3] Morey AF, Brandes S, Dugi DD, et al. Urotrauma: AUA guideline. J Urol. 2014; 192: 327-35. doi: 10.1016/j.juro.2014.05.004.

[4] Tekgul S, Riedmiller H, Dogan HS, et al. EAU guidelines on pediatric urology 2013. http:// uroweb.org/wp-content/uploads / 22 Paediatric-Urology_LR.pdf. Accessed April 7, 2016.

[5] Keller MS, Eric Coln C, Garza JJ, Sartorelli KH, Christine Green M, Weber TR. Functional outcome of nonoperatively managed renal injuries in children. J Trauma 2004; 57: 108-10.

[6] El-Sherbiny MT, Aboul-Ghar ME, Hafez AT, Hammad AA, Bazeed MA. Late renal functional and morphological evaluation after nonoperative treatment of high-grade renal injuries in children. BJU Int 2004; 93: 1053-6.

\section{Appendix A}

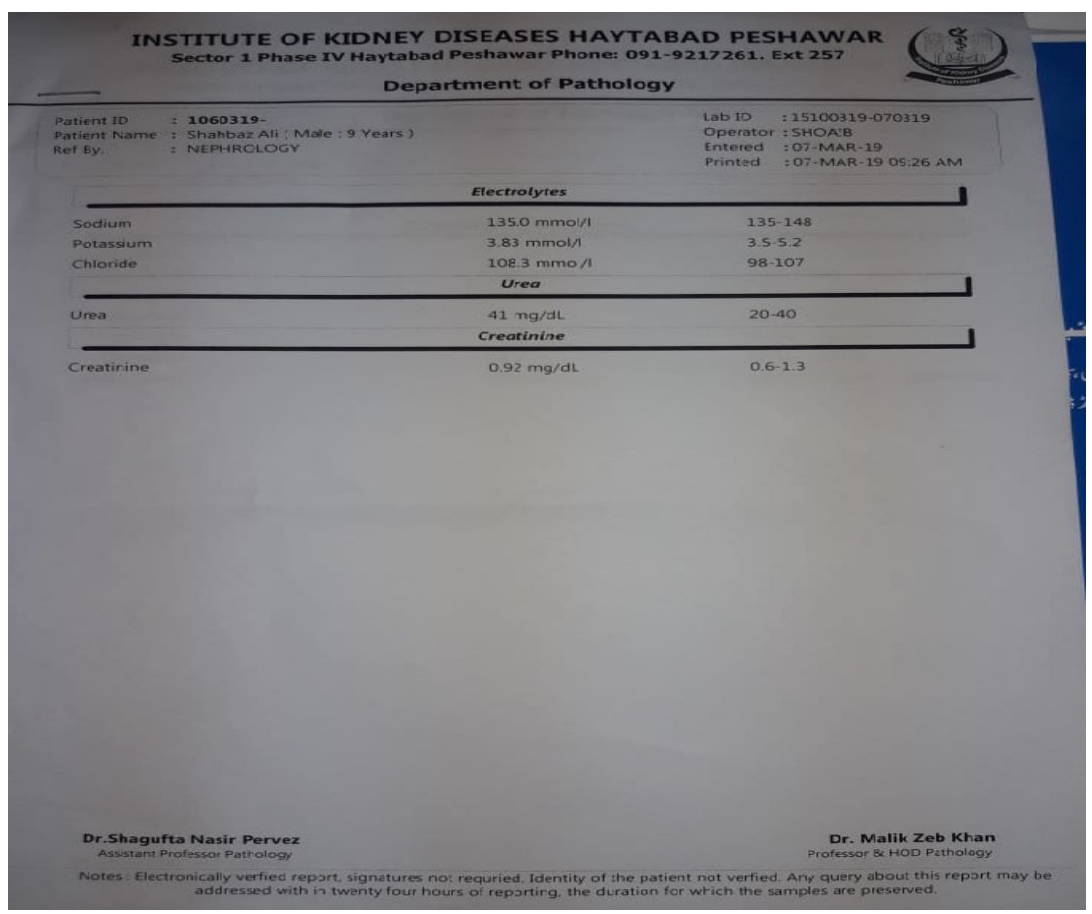

Citation: Prof. Dr. Bakhtawar Gul, FRCS, Dr. Riaz Ahmad Khan, FCPS, et al. Grade IV Renal Trauma in Pediatric Age Patient with a Solitary Kidney. Archives of Urology. 2019; 2(1): 8-11.

Copyright: (C) 2019 Prof. Dr. Bakhtawar Gul, FRCS, Dr. Riaz Ahmad Khan, FCPS, et al. This is an open access article distributed under the Creative Commons Attribution License, which permits unrestricted use, distribution, and reproduction in any medium, provided the original work is properly cited. 